\title{
Contingency-constrained Congestion Management and Transmission Cost Allocation
}

\section{Oana Pop, Constantin Barbulescu, Stefan Kilyeni, Antheia Deacu}

Politehnica University Timisoara, 2 Bd. V. Parvan, Timisoara, Romania, oana.pop@upt.ro, constantin.barbulescu@upt.ro, stefan.kilyeni@upt.ro

\begin{abstract}
Open access to the transmission network represents one of the important tasks for transmission and system operators. Moreover, increases of transactions in markets may lead to transmission network congestion. The approaches proposed for transmission congestion management are: generated power re-dispatching, generators outside the congested area dispatching, or consumed power mitigation for specific buses where it is possible. Transmission costs are able to be computed once the congestion has been solved and it is allocated to generators and consumers, using various methods. This paper analyzes congestion occurrence in case of $N-1$ contingencies and the allocation of transmission costs, using pro-rata and Bialek methods. The case study is performed for an existing large-scale system - the SouthernWestern side of the Romanian Power System. The results are relevant to for the Romanian TSO (Transmission System Operator) - Romanian Power Grid Company Transelectrica.
\end{abstract}

Keywords: congestion management; transmission system; $N-1$ criteria; cost allocation

\section{Introduction}

Currently, electric power systems around the world are subject to radical changes, moving from a monopolistic and regulated industry to a new model characterized by competition and open access to the transmission network. These facts are responsible for an increased number of transactions between market participants, under the optimal use of transmission facilities [1].

An important number of power transactions have been anticipated in the context of increased competition [2], [3] and this may lead to an overloading of transmission lines. These overloads will cause the system to exceed allowable thermal limits, stability and voltage limits, which can affect power transmission equipment.

These limits are power flow constraints and they depend on the power system operating condition at any given moment [4], [5]. Contingency limits ensure that no other system element is overloaded, once another one is disconnected. Thus, $\mathrm{N}-1$ and $N-2$ criteria must be satisfied. These constraints have to be fulfilled by the transmission network operator to ensure safety and power balance in the system. 
The problem of congestion also has an economic dimension [6], [7]. If there are no overloads within the system, then marginal costs corresponding to buses have very close values. The differences occur due to transmission losses. In this case, the generated power will be distributed depending on the offered price (classic power flow optimization). The congestion occurrence will lead to an important growth of the marginal costs and the generated power distribution will depend not only on the offered price, but also on the congestion "cost". The system operator will act to eliminate the congestion. Congestion management methods are generally divided into two main groups [28], [29]: preventive and corrective methods. The latter are used to remove the occurred congestion by generated power re-dispatching or consumed power mitigation.

A sensitive issue related to power transmission open access is represented by the transmission cost allocation [8], [9]. The use of transmission network by market participants is associated with transmission pricing, including: operating and capital costs, congestion costs, ancillary service costs, loss compensation costs, balancing system costs and stranded costs. Currently, there are numerous studies that have synthesized transmission-pricing issues with many internationally accepted options and practices. Postage stamp pricing [10] has the simplest design, and hence is the most common in immature power markets. In postage stamp pricing, all points are equivalent in terms of connection and use of the system network. The postage stamp area is generally a country or a controlled area.

Reference [11] and [12] present the power flow based on the MW-mile method. It was firstly proposed by Shirmohammadi. The MW-mile method is an embedded cost method. It computes transaction charges based on the transmission capacity use as a function of transacted power magnitude, the path followed and the distance travelled by transacted power. The MVA-mile method includes charging for reactive power, in addition to the charging for real power. The pro-rata method, presented in [13], allocates costs to generators and consumers according to the sum of real produced power and/or consumed by each generator and/or consumer.

The proportional sharing principle-based methods use Kirchhoff's Laws. These are known as tracing methods, the main versions of which are the Bialek and Kirschen methods. The Bialek tracing method computes the real and reactive generated power percentage supplied to a particular consumer. It includes two algorithms: upstream-looking algorithm (generation-load) or downstream-looking algorithm (load-generation) [14]-[17]. In the case of the first algorithm, the costs for the transmission network usage are allocated to individual generators and real power losses are allocated to consumers. The downstream-looking algorithm allocates the transmission network using costs to individual consumers, and real power losses are allocated to generators. The Kirschen method [18], [19] organizes the network buses and branches in homogeneous groups according to the following concepts: domain of generator, commons and links.

The distribution factor methods are power flow based. Distribution factors are used to determine the impact of generation and load on transmission power flow. 
Generally, generation distribution factors have been used in security and contingency analyses. The traditional version of this method was proposed by $\mathrm{Ng}$ in [20]. It was extended to AC power flow, being able to evaluate the real and reactive power flow [21]. Allocation method based on the equivalent bilateral exchanges (EBE) [22] does not depend on the slack bus selection. Also, it offers the counter-flow acceptance or exclusion option and network elements dependence. In recent years, methods based on system matrices $\left|\underline{Y}_{n}\right|$ or $\left|\underline{Z}_{n}\right|$ have received great attention, since these methods are able to integrate the network characteristics and circuit theories into real and reactive power and transmission losses allocation [24]-[26].

This paper proposes the congestion analysis in case of $N-1$ contingencies. The case study is performed on a large-scale power system, including the Western, South-Western and North-Western parts of the Romanian Power System. The necessary measures to eliminate the congestions are indicated. The authors use the Bialek method and pro-rata method to determine the usage costs of each branch allocated to generators and consumers.

The paper is organized as follows. The second section outlines the implemented transmission cost allocation methods. Section three is dedicated to the case study. The occurrence of congestion is presented along with suggested measures to eliminate them. Two operating conditions are considered: the first containing the congestion, and the last with the congestion solved. Using the methods presented within the previous sections, the network usage results are discussed for both operating conditions. The usage cost for generators and consumers are computed using Romanian OTS transmission tariffs. Conclusions are synthesized in Section four.

\section{Transmission Cost Allocation Method}

Over recent years different proposals have appeared pertaining to allocation and transmission usage costs. This section presents two transmission cost allocation approaches: the Bialek and the pro-rata methods. In both cases it is necessary to decide how much of the cost should be assigned to generators and how much to consumers. For example, in Romania, the share of the transmission cost for system usage is as follows: $20.69 \%$ to generators and $79.31 \%$ to consumers.

\subsection{The Bialek Method}

Consider the $i$-j branch connecting the sending bus, $i$, with the receiving bus, $j$. Both buses are connected to the rest of the system. $P_{i j}$ represents the real $i-j$ power flow. The $i$-j branch loss is $\Delta P_{i j}=\left|P_{j i}\right|-\left|P_{i j}\right|$. The gross power is defined as the sum between the consumed power and the part allocated from total transmission losses.

The gross real power flow through bus $i, P_{i}^{b}$ is expressed as [23]: 
$P_{i}^{b}=\sum_{j \in N_{i}}\left|P_{i j}^{b}\right|+P_{g i} ; \quad i \in N$

where $N_{i}$ is the subset of buses supplying directly bus $i, P_{i j}^{b}$ is the gross real branch flow through the network elements $i-j$ and $P_{g i}$ is the real generated power in bus $i$.

The term $\left|P_{i j}^{b}\right|$ can be replaced by $\left(P_{i j}^{b} / P_{j}^{b}\right) P_{j}^{b}$. Considering the real power losses, relation (1) becomes:

$$
P_{i}^{b}-\sum_{i \in N_{i}}\left(\frac{\left|P_{j i}\right|-\Delta P_{i j}}{P_{j}} \cdot P_{j}^{b}\right)=P_{g i}
$$

where $P_{j i}$ is the real power flow through the $i-j$ network elements and $P_{j}$ is the real power injected in bus $j$.

The matrix form of relation (2) is:

$P_{g}=A^{\mathrm{g}-\mathrm{c}} \cdot P^{b}$

where $P^{b}$ - is the gross bus flow matrix, $P_{g}$ - is the bus generation matrix, and $A^{g-c}$ is the upstream distribution matrix, having its elements defined by relation:

$$
a_{\mathrm{ij}}^{\mathrm{g}-\mathrm{c}}=\left\{\begin{array}{l}
1 \quad \text { if } \quad i=j \\
-\frac{\left|P_{j i}\right|-\Delta P_{i j}}{P_{j}} \quad \text { if } \quad i>j, j \in N_{i} \\
0 \quad \text { if } \quad i>j, j \notin N_{i} \text { or } i<j
\end{array}\right.
$$

Considering relation (3) $P_{i}^{b}$ yields for each bus:

$$
P_{i}^{b}=\sum_{k \in \mathrm{N}}\left(a i_{\mathrm{ik}}^{\mathrm{g}-\mathrm{c}} \cdot P_{g k}\right) ; \quad i \in N
$$

The usage of any branch $l$ allocated to the generator at bus $k$ can be expressed as:

$$
U_{l}^{g-c}=\frac{1}{5} \frac{\left|P_{i j}\right|}{P_{j}} \cdot a i_{\mathrm{ik}}^{\mathrm{g}-\mathrm{c}} \cdot P_{g k}
$$

The net power is defined as the difference between the generated power and the part allocated from total transmission losses. The net real power flow through bus $i$, $P_{i}^{n}$, can be expressed as:

$$
P_{i}^{n}=\sum_{j \in N_{i}}\left|P_{i j}^{n}\right|+P_{c i} ; \quad i \in N
$$


where $N_{i}$ is the subset of buses supplying bus $i$ directly, $P_{i j}^{n}$ is the net real branch flow through the network elements $i-j ; P_{c i}$ is real consumed power at bus $i$.

As an analogy with the previous algorithm, the relation (7) can be written as:

$$
P_{i}^{n}-\sum_{i \in N_{i}}\left(\frac{\left|P_{j i}\right|-\Delta P_{i j}}{P_{j}} \cdot P_{j}^{b}\right)=P_{c i}
$$

In matrix form this means:

$$
P_{c}=A^{c-g} \cdot P^{n}
$$

where $P^{n}$ is the net bus flow array, $P_{c}$ is the consumed power array and $A^{\mathrm{c}-\mathrm{g}}$ is the downstream distribution matrix, its elements are defined as follows:

$$
a_{\mathrm{ij}}^{\mathrm{c}-\mathrm{g}}=\left\{\begin{array}{l}
1 \quad \text { if } \quad i=j \\
-\frac{\left|P_{j i}\right|-\Delta P_{i j}}{P_{j}} \quad \text { if } \quad i<j, j \in N_{i} \\
0 \quad \text { if } \quad i<j, j \notin N_{i} \text { or } i>j
\end{array}\right.
$$

From relation (9), $P_{i}^{n}$ results for each bus:

$$
P_{i}^{n}=\sum_{k \in \mathrm{N}}\left(a i_{\mathrm{ik}}^{\mathrm{c}-\mathrm{g}} \cdot P_{c k}\right) ; \quad i \in N
$$

The usage of any branch $l$ allocated to the generator at bus $k$ can be expressed as:

$$
U_{l}^{c-g}=\frac{4}{5} \frac{\left|P_{i j}\right|}{P_{j}} \cdot a i_{\mathrm{ik}}^{\mathrm{c}-\mathrm{g}} \cdot P_{c k}
$$

The cost of branch $k$ allocated to generators and consumers at bus $i$ and $j$ is:

$$
C_{k}^{G}=\sum_{i \in G} c_{g i} \cdot U_{l}^{g-c}, \quad C_{k}^{D}=\sum_{j \in D} c_{c j} \cdot U_{l}^{c-g}
$$

where $c_{g i}-$ transmission costs for injected power in bus $i$ [\$/MWh]; $c_{c j}-$ transmission cost for extracted power in bus $j[\$ / \mathrm{MWh}]$

\subsection{Pro-Rata Method}

Interconnected network users adopt the pro-rata method [15]. Transmission costs are allocated proportionally to the power injected by each generator or by each consumer. The branch $k$ network usage allocated to generator $i$ or consumer $j$ is determined by the following relations: 


$$
U G_{i k}=\frac{1}{5} \frac{P_{g i}}{\sum_{i \in G} P_{g i}} U G_{k}, U D_{j k}=\frac{4}{5} \frac{P_{c j}}{\sum_{j \in D} P_{c j}} U D_{k}
$$

where $P_{g i}$ is the generated power in bus $i, P_{c j}$. is the consumed power in bus $j, G$ is the subset of PV buses and $C$ is subset of PQ buses.

The cost of branch $k$ allocation to generators and consumers at bus $i$ and $j$ is:

$$
C_{k}^{G}=\sum_{i \in G} c_{g i} \cdot U G_{i k}, \quad C_{k}^{D}=\sum_{j \in D} c_{c j} \cdot U D_{j k}
$$

\section{Case Study}

The case study is performed for the Western and South-Western side of the Romanian Power System [28], [29], which has 88 buses and 107 branches. The 35 PV buses are divided into 17 real generating units and 18 equivalent $\mathrm{PV}$ buses, obtained by extracting the analyzed part from the Romanian Power System. The system has $42 \mathrm{PQ}$ buses. The buses at medium voltage (real generating groups), $220 \mathrm{kV}, 400 \mathrm{kV}$ are represented. At $110 \mathrm{kV}$ level, only the generated and consumed powers are considered.

The operating condition presented in Figure 1 corresponds to the disconnection of the 400/220 kV Rosiori autotransformer [28]. On the $220 \mathrm{kV} 28087-28093$ overhead line (OHL) there is an overload of $126 \%$. An inadmissible voltage level is recorded for 28094,28095 and 28093 buses area $(182.6 \mathrm{kV}, 184.6 \mathrm{kV}$ and $185.4 \mathrm{kV})$. The hourly cost of the power system is $121478 \$ / \mathrm{h}$ and the penalty cost is $47363 \$ / \mathrm{h}$. As was expected, the maximum value of nodal marginal princes is recorded for 28095 PQ bus (1760 \$/MWh) and the lowest value is registered for bus 29102 (31 \$/MWh). Other areas with nodal marginal price high values are mentioned in the cases of buses 28093 (1601 \$/MWh, 1643 \$/MWh, $1663 \$ / \mathrm{MWh}$ ), 28094 (1630\$/MWh) and 28095 (1692 \$/MWh).

The power consumption in 28093 and 28095 buses area has been reduced by the TSO: $6 \mathrm{MW}$ in 28484, 28485, 28093 and 28491 buses in order to eliminate congestion. The hourly cost value is $116299.61 \$ / \mathrm{h}$. All local marginal prices are around $30 \$ / \mathrm{MWh}$.

Furthermore, the generated power at 29169, 29260, 29262, 28036, 29159, 29160, 29119,29121 and 29238 bus groups has been reduced. In the case of the 29189-29193, 29250, 29232, 29233 and 29162 PV buses, the power has been increased. Another category of groups has the same value $(28795,28709,28719,28756,28562,29232$ and 29233 buses). Figure 2 presents the generated power re-dispatching mechanism.

Mathematica ${ }^{\circledR}$ environment is used to compute the transmission costs allocated to generators and to consumers for both operating conditions. The software tool Tracing for Real and Reactive Power (TAPQ) has been developed by the authors [29] and is linked with PowerWorld software. The database containing the power system 


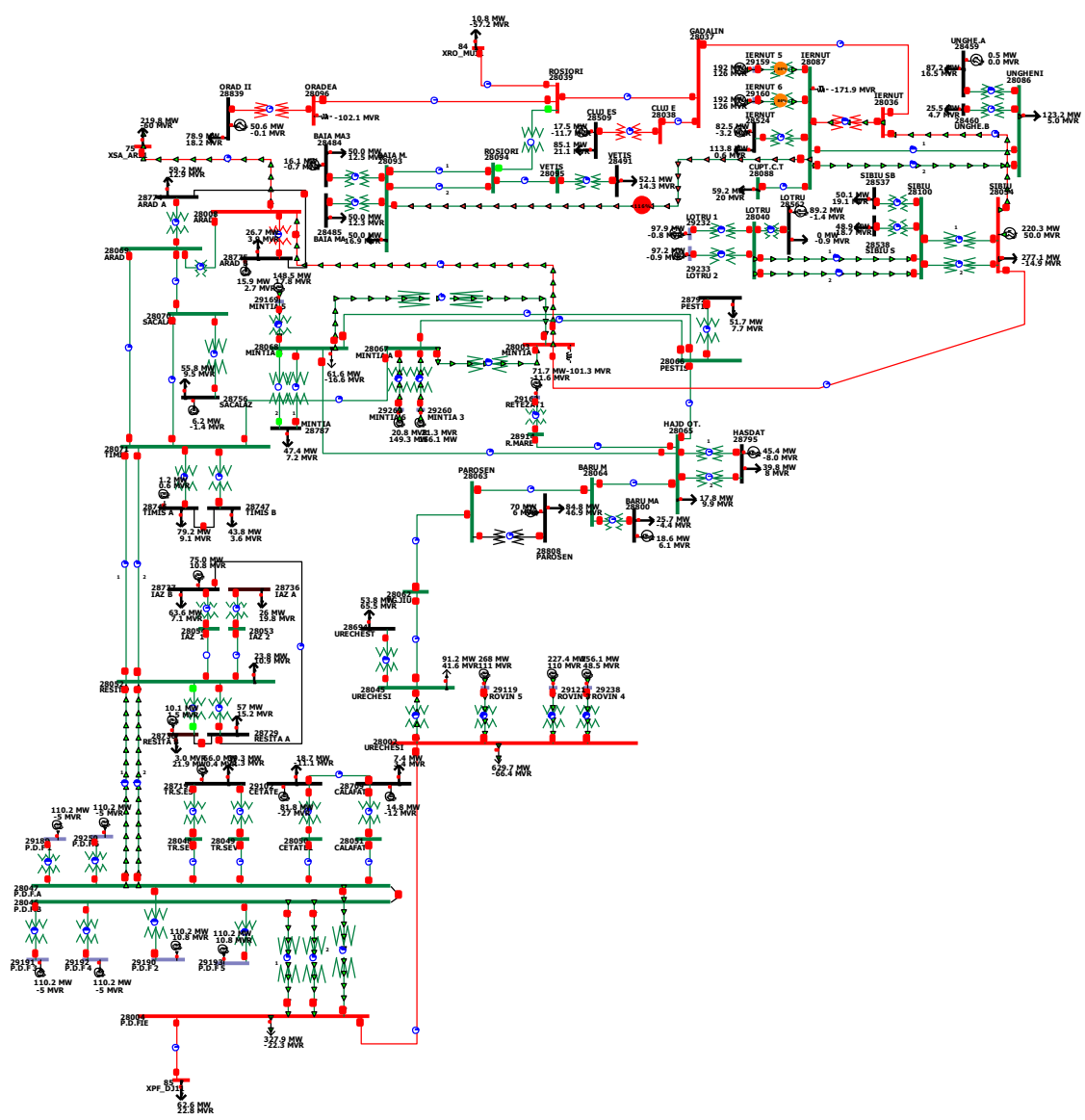

Figure 1

Operating condition with congestion on 28087-28093 OHL

topology and parameters is extracted from Powerworld software and transmission cost allocation methods are launched. In instances of pro-rata method, network usage allocated to generators and consumers and transmission cost allocation are going to be computed. The Bialek method-computing algorithm contains the following steps:

1. Extract the $P_{j i}$, real power flow and $P_{j}$, real injected power;

2. Upstream distribution matrix elements and matrix form determination;

3. Gross bus flows array obtaining;

4. Network usage computing for all branches using relation (6), in case of generators;

5. Downstream distribution matrix elements and matrix form determination;

6. Net bus flow array obtaining;

7. Network usage computing for all branches using relation (12), in case of consumers;

8. Transmission cost allocated to generators and consumers.

The upstream and downstream matrices dimension is 88 lines and columns, in case of the analyzed operating conditions. 


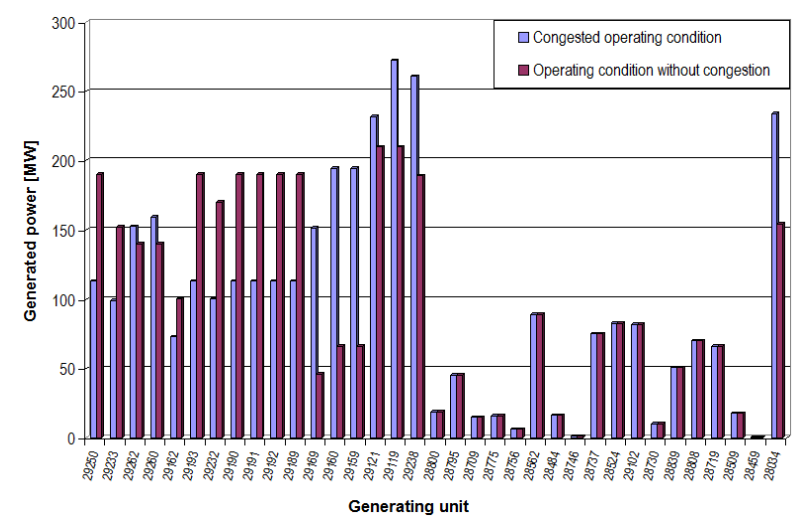

Figure 2

Generated power re-dispatching

Only a computing synthesis is going to be presented in the following. A case study power system detail is shown in Figure 3, which is used to clarify the pro-rata and Bialek methods. This figure provides additional generators, loads and power flow data.

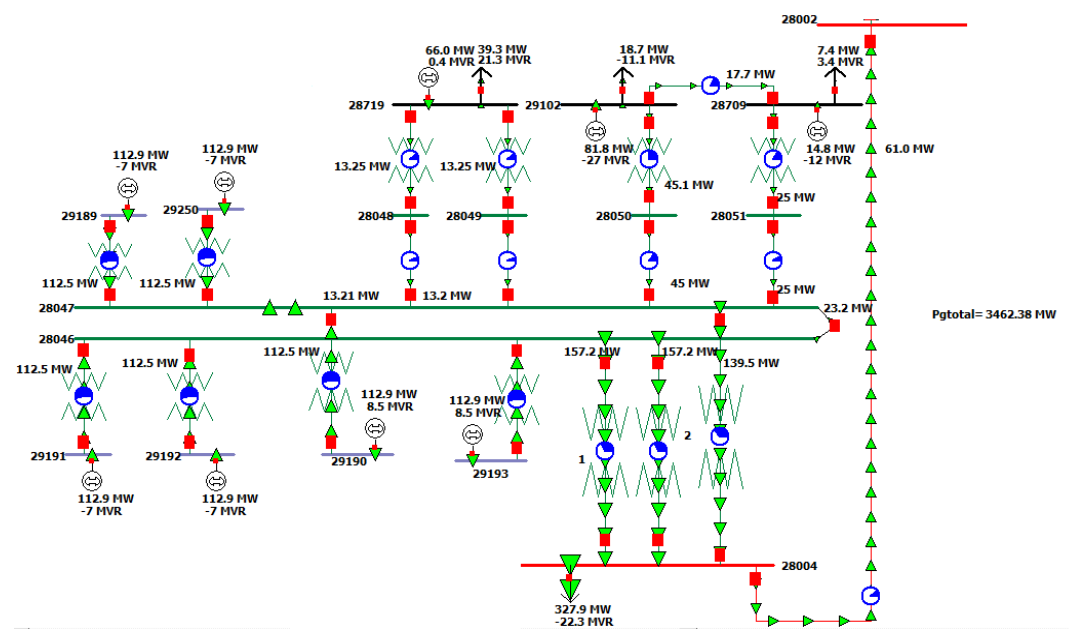

Figure 3

Power system detail. Congestion on 28087-28093 OHL

With the pro-rata method, OHL network usage 28002-28004, allocated to generator 29189 and load bus 28002 is determined as follows:

$$
\begin{aligned}
& U G_{29189 \text { (branch 28002-28004) }}=\frac{1}{5} \frac{P_{g 29189}}{\sum_{i \in G} P_{g i}} U G_{28002-28004}=\frac{1}{5} \cdot \frac{112.926}{3462.37} \cdot 61=0.3979 \mathrm{MW}, \\
& U D_{28002 \text { (branch 28002-28004) }}=\frac{4}{5} \frac{P_{\mathrm{c} 28002}}{\sum_{j \in D} P_{c j}} U D_{28002-28004}=\frac{4}{5} \cdot \frac{629.7}{3398.1} \cdot 61=0.0431 \mathrm{MW}
\end{aligned}
$$


The Bialek method upstream distribution matrix elements are determined as (relation 4):

$$
\begin{aligned}
& a_{28046-29191}^{\mathrm{g}-\mathrm{c}}=-\frac{112.5}{112.9}=-0.9965 \\
& a_{29191-28046}^{\mathrm{g}-\mathrm{c}}=-\frac{112.5}{112.5+112.5}=-0.5000 \\
& a_{28004-28047}^{\mathrm{g}-\mathrm{c}}=-\frac{139.5}{23.2+25+45+13.2+13.2+112.5+112.5+112.5}=-0.2461 \\
& a_{28004-28046}^{\mathrm{g}-\mathrm{c}}=-\frac{157.2+157.2}{112.5+112.5+112.5}=-0.9316 \\
& a_{29191-28047}^{\mathrm{g}-\mathrm{c}}=0 \\
& a_{29191-29191}^{\mathrm{g}-\mathrm{c}}=1 \\
& a_{28002-28004}^{\mathrm{g}-\mathrm{c}}=-\frac{61}{157.2+157.2+139.5}=-0.1344
\end{aligned}
$$

Any branch usage allocated to generator and consumer can be determined in two ways: by applying relations (6) and (12) or by directly applying a proportional sharing principle. In the following, the case of proportional sharing principle is presented. As shown in Figure 4, bus 1 is connected to upstream buses 2 and 3 and downstream buses 4 and 5, by four branches. Bus 1 real power flow is denoted by $P_{2-1}$ and $P_{3-1}$, respectively, while real power flowing out of bus 1 is denoted by $P_{1-4}$ and $P_{1-5}$.

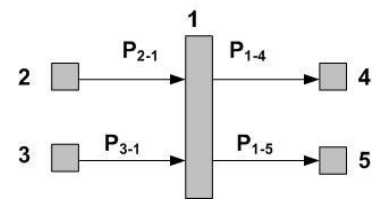

Figure 4

Proportional sharing principle

Buses 2, 3, 4 and 5 can be either PV or PQ buses, supplying or being supplied from bus 1 . According to the proportional sharing principle, inflows are shared proportionally between the outflows in following manner:

- $P_{1-4}$ is determined by two components:

$$
\frac{P_{2-1}}{P_{2-1}+P_{3-1}} \cdot P_{1-4} \text { coming from } P_{2-1} ; \frac{P_{3-1}}{P_{2-1}+P_{3-1}} \cdot P_{1-4} \text { coming from } P_{3-1} \text {; }
$$

- $P_{1-5}$ is determined by two components:

$$
\frac{P_{2-1}}{P_{2-1}+P_{3-1}} \cdot P_{1-5} \text { coming from } P_{2-1} ; \frac{P_{3-1}}{P_{2-1}+P_{3-1}} \cdot P_{1-5} \text { coming from } P_{3-1} \text {. }
$$

Following power flow direction, the generator and consumer contributions computing process starts from bus 29102. Generator contribution from bus 28719 on branches 
28719-28048 ( $\left.P_{\text {branch(28719-28048) }}^{G_{22819}}\right), 29102-28049\left(P_{\text {branch(29102-28049) }}^{G_{28719}}\right), 28048$ $28047 \quad\left(P_{\text {branch(28048-28047) }}^{G_{28719}}\right) \quad$ and $28049-28047 \quad\left(P_{\text {branch(28049-28047) }}^{G_{28719}}\right)$ respectively is the same: 13.25 MW. As shown in Figure 3, generator 29102 uses branches 29102-28050, 28050-28047 and 29102-28709. Its contributions are $45 \mathrm{MW}$, $45 \mathrm{MW}$ and 17.7 MW.

In the following, the contributions of generators 29102 and 28709 on branch 28709-28051, and bus local consumer 28709 are shown.

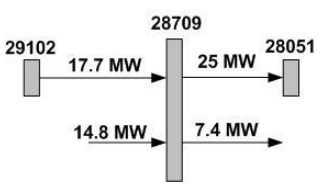

Figure 5

Bus 28709

The contribution of generator $29102\left(P_{\text {branch(28709-28051) }}^{G_{22102}}\right)$ and consumer 28709

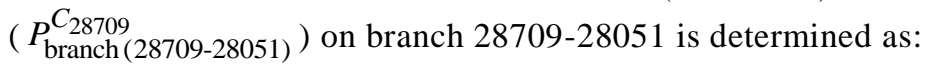

$$
\begin{aligned}
P_{\text {branch(28709-28051) }}^{G_{29102}} & =\frac{P_{\text {branch (29102-28709) }}}{P_{\operatorname{branch}(29102-28709)}+P_{\mathrm{G}_{29102}}} \cdot P_{\operatorname{branch}(28709-28051)}= \\
& =\frac{17.7}{14.8+17.7} \cdot 25=13.6154 M W \\
P_{\text {branch(28709-28051) }}^{C_{28709}} & =\frac{P_{\mathrm{G}_{29108}}}{P_{\text {branch }(29102-28709)}+P_{\mathrm{G}_{29108}}} \cdot P_{\operatorname{branch}(28709-28051)}= \\
& =\frac{14.8}{14.8+17.7} \cdot 7.4=4.0302 M W
\end{aligned}
$$

The consumer from bus 28709 is supplied from generator 29109, through branch 29102-28709 (4.0302 MW). The remaining power, $3.3698 \mathrm{MW}$, belongs to the local generator from bus 29109.

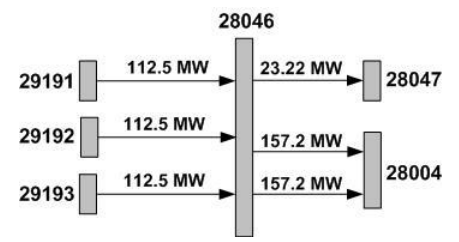

Figure 6

Bus 28046

According to Figure 6, bus 28046 is connected to three upstream generator buses (29191, 29192 and 29193) and another two downstream buses (28047, 28004). 
The contribution of generators from buses 29191, 29192, 29193 on branch 2804628047 has the same value (7.7333 MW):

$$
\begin{aligned}
P_{\text {branch (28046-28047) }}^{G_{29191}} & =\frac{P_{\mathrm{G}_{29191}}}{P_{\mathrm{G}_{29191}}+P_{\mathrm{G}_{29192}}+P_{\mathrm{G}_{29193}}} \cdot P_{\operatorname{branch}(28046-28047)}= \\
& =7.7333 \mathrm{MW}
\end{aligned}
$$

104.8 MW is obtained in case of branch 28046-28004.

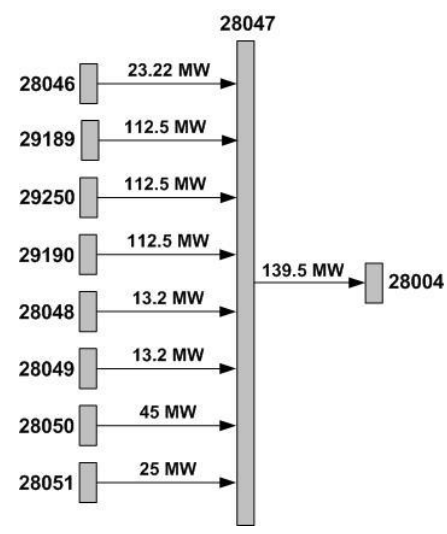

Figure 7

Bus 28047

In the case of branch 28047-28004, the contribution of generators 29189, 28250, 28190 and 28719 is performed in the same manner (Figure 7). The contribution of generator 29102 on branch 28047-28004, represents the contribution of the sum on branches 28050-28047 and 28051-28047.

$P_{\text {branch(28047-28004) }}^{\mathrm{G}_{29102}}=13.6381+4.1634=17.8015 \mathrm{MW}$.

The 28051-28047 branch remaining value belongs to generator $28709-3.481 \mathrm{MW}$. Generator contribution determination requires an additional computation. Firstly, the contribution of branch 28046-28047 on branch 28047-28004 $P_{\text {branch (28047-28047) }}^{\text {branch(2804) }}$ has been computed.

$P_{\text {branch }(28047-28004)}^{\operatorname{branch}(28046-28047)}=7.0943 M W$

Then, the contributions of the three generators on branch 28047-28004 are obtained.

$$
\begin{aligned}
P_{\mathrm{branch}(28047-28004)}^{\mathrm{G}_{29191}} & \frac{P_{\mathrm{branch}(28047-28004)}^{\operatorname{branch}(28046-28047)}}{P_{\mathrm{branch}(28046-28047)}} \cdot P_{\mathrm{branch}(28046-28047)}^{G_{29191}}= \\
& =\frac{7.0943}{23.22} \cdot 7.7333=2.3648 \mathrm{MW}
\end{aligned}
$$


The sum of the generators' contributions on branch 28047-28004 is:

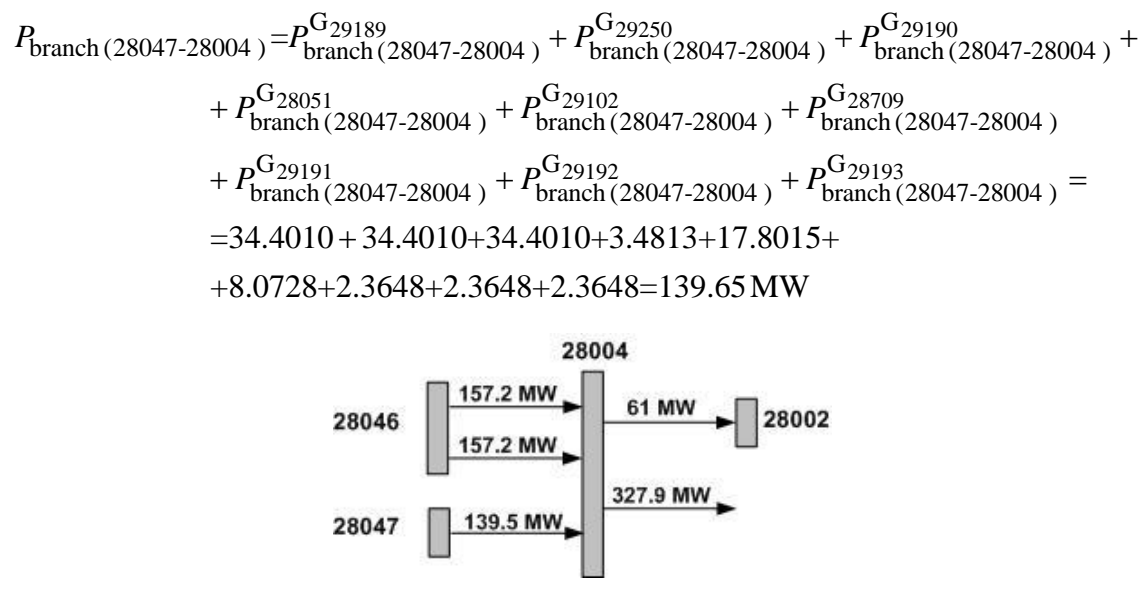

Figure 8

Bus 28004

Contributions on branch 28004-28002 and local consumer 28004 can be obtained using branches 28046-28004 and 28047-28004, as is shown in Figure 8.

$$
\begin{aligned}
& P_{\text {branch (28004-28002) }}=P_{\operatorname{branch}(28004-28002)}^{\mathrm{G}_{29189}}+P_{\mathrm{branch}(28004-28002)}^{\mathrm{G}_{29250}}+P_{\mathrm{branch}(28004-28002)}^{\mathrm{G}_{29190}}+ \\
& +P_{\mathrm{branch}(28004-28002)}^{\mathrm{G}_{28051}}+P_{\mathrm{branch}(28004-28002)}^{\mathrm{G}_{22102}}+P_{\mathrm{branch}(28004-28002)}^{\mathrm{G}_{28709}} \\
& +P_{\mathrm{branch}(28004-28002)}^{\mathrm{G}_{2919}}+P_{\mathrm{branch}(28004-28002)}^{\left.\mathrm{G}_{2192}\right)}+P_{\mathrm{branch}(28004-28002)}^{\left.\mathrm{G}_{29193}\right)}= \\
& =4.6232+4.6232+4.6232+0.4679+2.3924+ \\
& +1.0849+14.402+14.402+14.402=61 \mathrm{MW} \\
& P_{C_{28004}}=P_{C_{28004}}^{\mathrm{G}_{29189}}+P_{C_{28004}}^{\mathrm{G}_{29250}}+P_{C_{28004}}^{\mathrm{G}_{2919}}+P_{C_{28004}}^{\mathrm{G}_{28051}}+P_{C_{28004}}^{\mathrm{G}_{29102}}+P_{C_{28004}}^{\mathrm{G}_{28709}}+P_{C_{28004}}^{\mathrm{G}_{29191}}+ \\
& +P_{C_{28004}}^{\mathrm{G}_{29192}}+P_{C_{28004}}^{\mathrm{G}_{29193}}=24.8515+24.8515+24.8515+2.5149+12.8599+ \\
& +5.8318+77.4164+77.4164+77.4164=328 \mathrm{MW}
\end{aligned}
$$

Values corresponding to generator contribution on consumers will not be used for transmission cost allocation. For example, local generators only supply consumer 28719. Thus, transmission cost allocation is 0 [ $\$ / \mathrm{h}]$. Only generator 29109 contribution to consumer 28709 , through branch $29102-28709$, will be used in transmission cost allocation.

In the following, Figures 9-16 present a selection of values corresponding to branch usage allocated to each generator and each consumer. The analysis is performed for OHLs 28003-28034 and 28002-28004, before and after congestion is solved.

It can be observed that in both cases PV buses 29169, 29260 and 29262 have a significant contribution on OHL 28003-28034, on the Bialek method. The contribution 
of these groups is increased from 20.34 MW to $40.57 \mathrm{MW}$. Using the pro-rata method, for the same OHL, 29119, 29121 and PV buses 29238 have the greatest influence on the transmission network usage. Once the congestion is solved the results are: 3.47 MW, 3.47 MW and 3.12 MW.

Figures 13-16 presents the OHL usage values allocated to consumers. The same OHLs (as in case of the generating units) have been considered within the analyses. The highest usage value is recorded for the PQ bus 28034 (Bialek method): 88.27 MW (operating condition with congestion) and $49.59 \mathrm{MW}$ (operating condition with congestion solved). It is explained by the fact that PQ bus 28034 is connected to OHL 28003-28034. With the pro-rata method, the significant contribution has been highlighted for the PQ bus 28002 (629.7 MW).

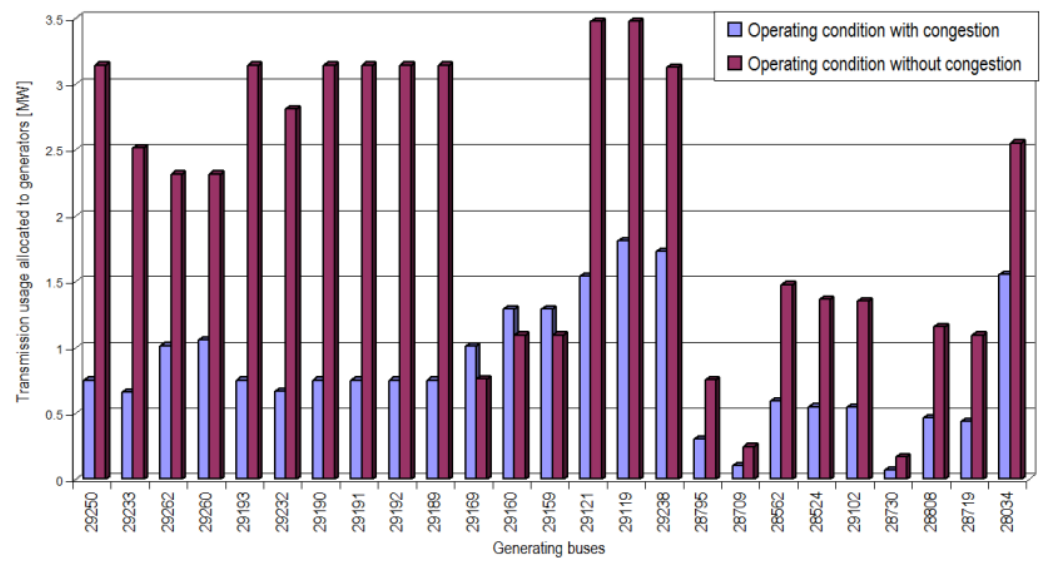

Figure 9

28003-28034 OHL usage allocated to generating groups using the pro-rata method

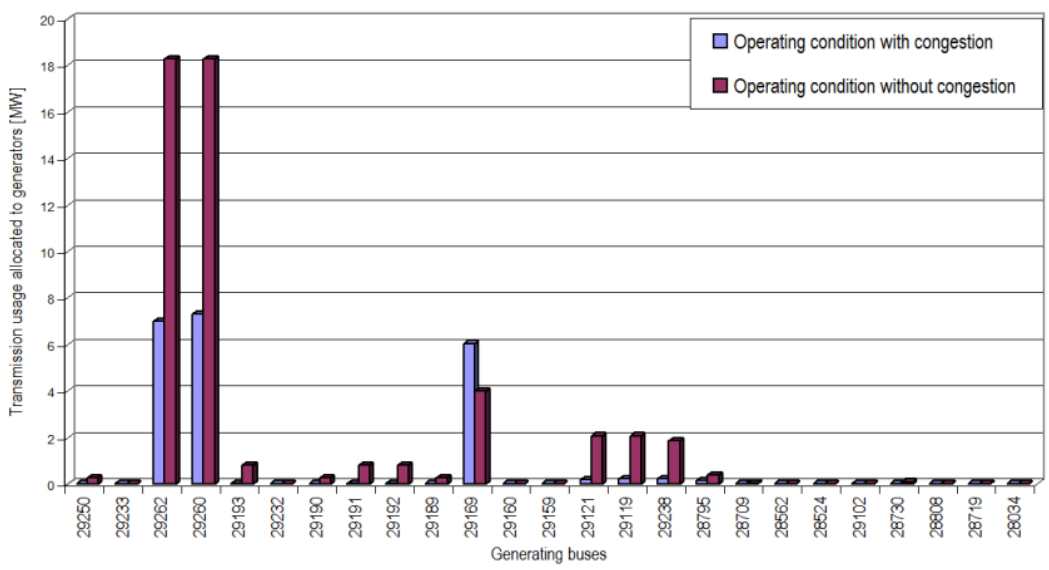

Figure 10

28003-28034 OHL usage allocated to generating groups using the Bialek method 


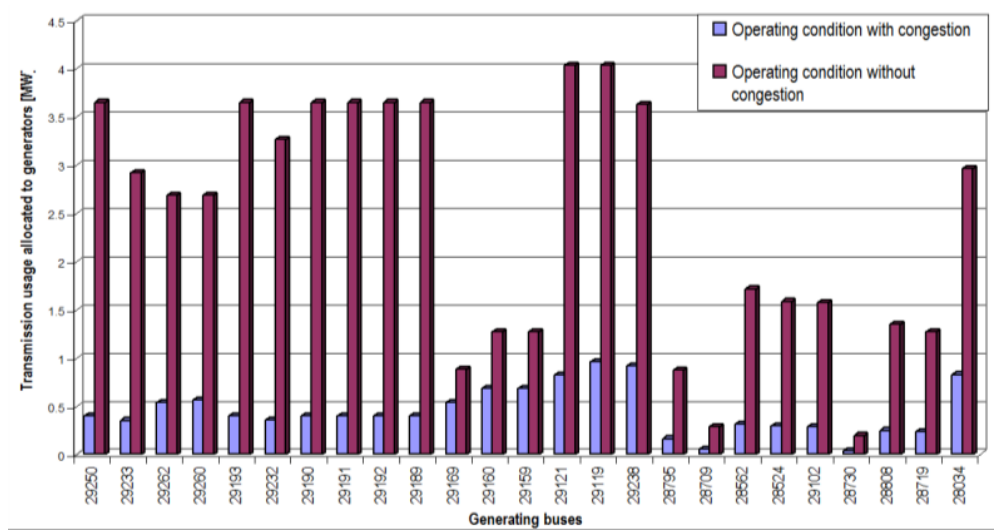

Figure 11

28002-28004 OHL usage allocated to generating groups using the pro-rata method

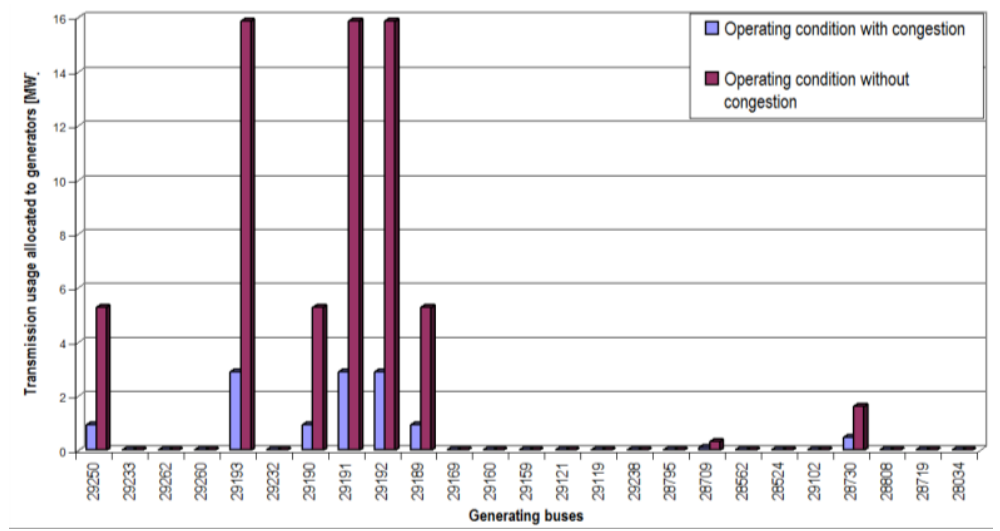

Figure 12

28002-28004 OHL usage allocated to generating groups using the Bialek method

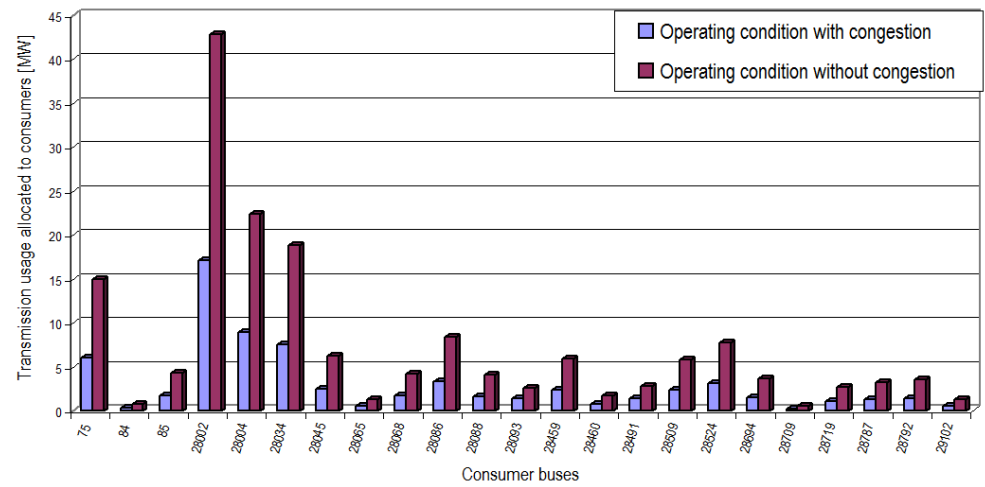

Figure 13

28003-28034 OHL usage allocated consumer buses using the pro-rata method 


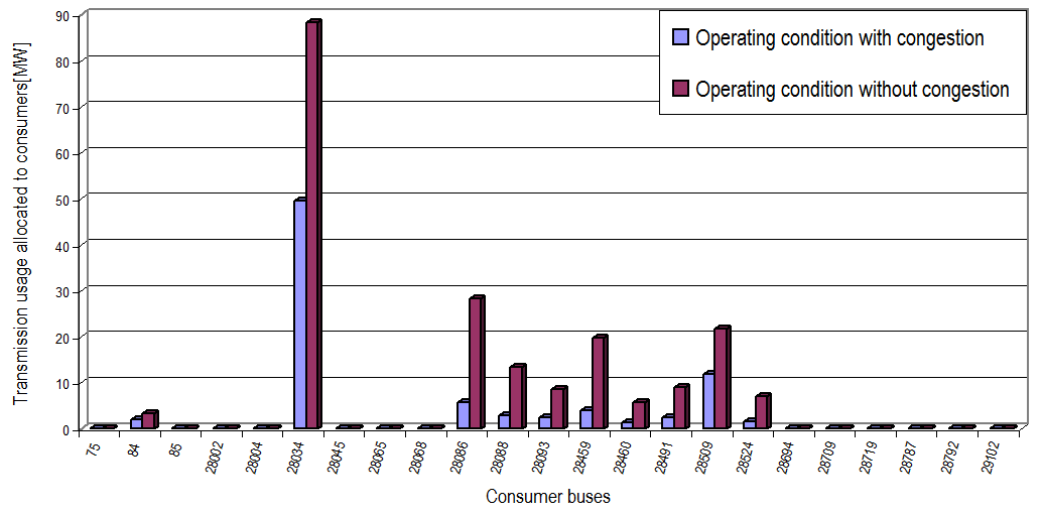

Figure 14

28003-28034 OHL usage allocated consumer buses using the Bialek method

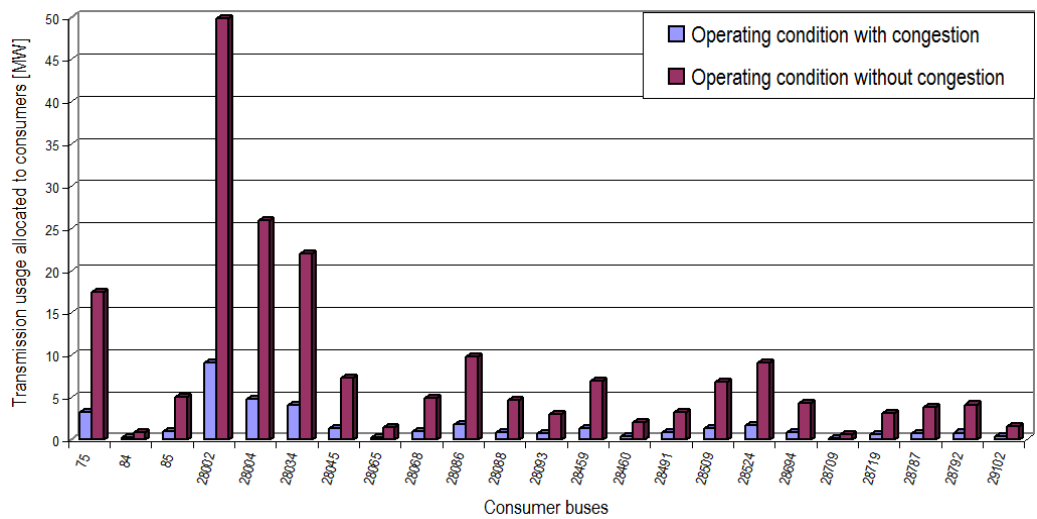

Figure 15

28002-28004 OHL usage allocated to consumer buses using the pro-rata method

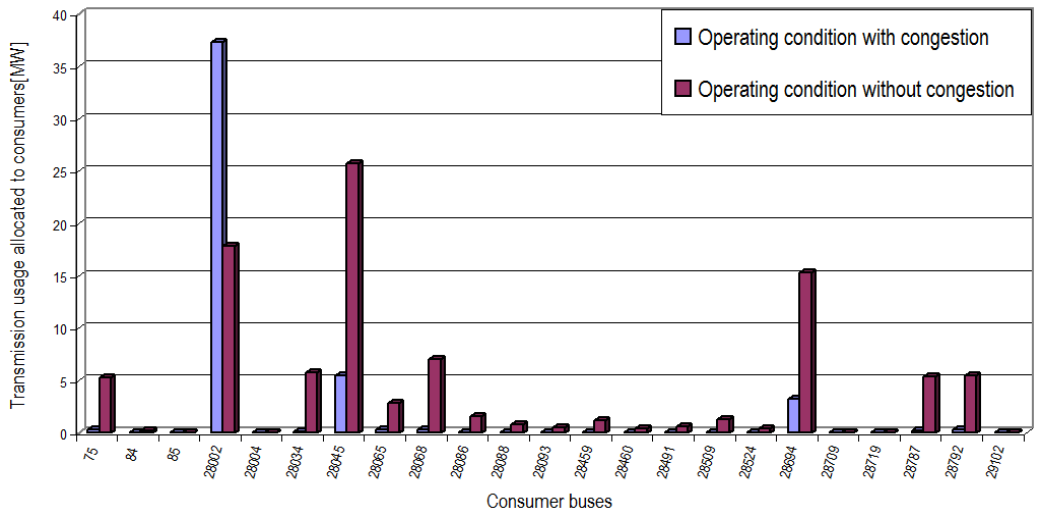

Figure 16

28002-28004 OHL usage allocated to consumer buses using Bialek method 
The transmission costs are computed for generators and consumers. The transmission tariffs used by the Romanian OTS have been considered. These tariffs cover operation, maintenance and development costs. Currently, the transmission tariff system is divided into six areas of generation and eight load areas. The transmission tariff values [27] corresponding to both areas are presented in Tables 1 and 2 respectively, and the results are presented in Tables 3 and 4.

Table 1

Generation area transmission tariff values

\begin{tabular}{|c|c|c|c|c|c|c|}
\hline Generation area & $1 \mathrm{G}$ & $2 \mathrm{G}$ & $3 \mathrm{G}$ & $4 \mathrm{G}$ & $5 \mathrm{G}$ & $6 \mathrm{G}$ \\
\hline $\begin{array}{c}\text { Transmission tariff } \\
\text { value }(\$ \mathrm{MWh})\end{array}$ & 21.154 & 14.998 & 22.150 & 30.841 & 19.193 & 25.107 \\
\hline
\end{tabular}

Table 2

Load area transmission tariff values

\begin{tabular}{|c|c|c|c|c|c|c|c|c|}
\hline Load area & $1 \mathrm{~L}$ & $2 \mathrm{~L}$ & $3 \mathrm{~L}$ & $4 \mathrm{~L}$ & $5 \mathrm{~L}$ & $6 \mathrm{~L}$ & $7 \mathrm{~L}$ & $8 \mathrm{~L}$ \\
\hline $\begin{array}{c}\text { Transmission tariff } \\
\text { value }(\$ / \mathrm{MWh})\end{array}$ & 35.820 & 33.527 & 24.564 & 31.837 & 33.436 & 33.587 & 35.005 & 26.345 \\
\hline
\end{tabular}

Using the Bialek method, generators 28756, 28484, 28746, 28730, 28839, 28808, 28509 and 28459 only supply the local consumers. For these generators the transmission cost is $0 \$ / \mathrm{h}$. According to the pro-rata method, the transmission cost allocation does not depend on network topology. For example, cost allocation for generator 28524 is 159.7 \$/h. Real generated power on buses 29119 and 29121 is $210 \mathrm{MW}$. Cost allocation to both generators is $835.94 \$ / \mathrm{h}$ (pro-rata method) and $665.28 \$ / \mathrm{h}$ (Bialek method). We should expect for both methods (pro-rata and Bialek), that the 29232 generator allocated cost $(486.02 \$ / \mathrm{h}$ and $701.56 \$ / \mathrm{h})$ would be much higher than the one allocated to generator 28034 (441.04 $\$ / \mathrm{h}$ and $316.46 \$ / \mathrm{h}$ ), because 29232 uses the transmission network in a higher degree. Real generated power in case of 29232 is $170 \mathrm{MW}$, and in the case of 28034 it is $154.3 \mathrm{MW}$.

Table 3

Transmission cost allocated to generators

\begin{tabular}{|c|c|c|c|c|c|c|c|c|c|}
\hline Generating units & 29250 & 29233 & 29262 & 29260 & 29162 & 29193 & 29232 & 29190 & 29191 \\
\hline Pro-rata & 756.34 & 434.84 & 400.26 & 400.26 & 285.9 & 756.34 & 486.02 & 543.2 & 756.34 \\
\hline Bialek & 986.5 & 627.84 & 560.28 & 560.28 & 493.42 & 813.54 & 701.56 & 986.5 & 813.48 \\
\hline Generating units & 29192 & 29189 & 29169 & 29160 & 29159 & 29121 & 29119 & 29238 & 28800 \\
\hline Pro-rata & 756.34 & 756.34 & 131.52 & 127.76 & 127.76 & 835.94 & 835.94 & 752.36 & 53.18 \\
\hline Bialek & 813.54 & 986.5 & 160.02 & 103.2 & 103.2 & 665.28 & 665.28 & 598.86 & 0.72 \\
\hline Generating units & 28795 & 28709 & 28775 & 28756 & 28562 & 28484 & 28746 & 28737 & 28524 \\
\hline Pro-rata & 129.8 & 58.92 & 45.46 & 17.72 & 255.02 & 31.16 & 3.44 & 214.42 & 159.7 \\
\hline Bialek & 21.94 & 73.38 & 0.62 & 0 & 368.58 & 0 & 0 & 18.66 & 0 \\
\hline Generating units & 29102 & 28730 & 28839 & 28808 & 28719 & 28509 & 28459 & 28034 & \\
\hline Pro-rata & 325.62 & 28.88 & 144.66 & 200.12 & 262.72 & 33.88 & 0.96 & 441.04 & 0 \\
\hline Bialek & 397.74 & 0 & 0 & 0 & 172.08 & 0 & 0 & 316.46 & 0 \\
\hline Total $[\$ / \mathrm{h}]$ & Pro rata & \multicolumn{3}{|c|}{11550.12} & Bialek & \multicolumn{4}{|c|}{12009.46} \\
\hline
\end{tabular}


The same analysis is performed with consumers located at buses 28491 (52.1 MW) and 28002 (629.7 MW), the second being characterized by an accentuated transmission network usage. Although PQ bus 28002 has a higher consumed power value, by using the Bialek method, the transmission cost allocated value (17196.48 $\$ / \mathrm{h})$ is smaller than bus $28034(17927.2 \$ / \mathrm{h})$. A cost reduction is due to its location within the power system. PQ bus 28002 is located near PV buses 29119, 29121, 29238, 29189, 29190, 29191, 29192, 29193 and 29250, with all generators having a significant contribution in supplying the area. According to the results presented in Table 4, transmission cost allocated to PQ buses 28719,28795 and 29102 is $0 \$ / \mathrm{h}$, because consumers are only supplied by local generators. The smallest transmission cost value is allocated to PQ $84(1.76 \$ / \mathrm{h}, 3.92 \$ / \mathrm{h})$, due to the smallest transmission network usage.

Table 4

Transmission cost allocated to consumers

\begin{tabular}{|c|c|c|c|c|c|c|c|c|c|}
\hline $\begin{array}{c}\text { Consumer } \\
\text { bus }\end{array}$ & 75 & 84 & 85 & 28002 & 28004 & 28034 & 28045 & 28052 & 28065 \\
\hline Pro-rata & 564 & 1.76 & 172.88 & 32846.48 & 17104 & 19674.64 & 4757.2 & 1609.04 & 1203.36 \\
\hline Bialek & 1072.72 & 3.92 & 162.72 & 17196.48 & 10769.68 & 17927.2 & 3916.8 & 1168 & 1707.76 \\
\hline $\begin{array}{c}\text { Consumer } \\
\text { bus }\end{array}$ & 28068 & 28086 & 28088 & 28093 & 28459 & 28460 & 28484 & 28485 & 28491 \\
\hline Pro-rata & 4164.48 & 8747.44 & 4222.32 & 2710.24 & 6191.36 & 1810.56 & 2710.24 & 2710.24 & 2860 \\
\hline Bialek & 5959.12 & 14265.92 & 6497.12 & 4321.68 & 11042.08 & 3179.2 & 3590.56 & 3978.08 & 6866.56 \\
\hline $\begin{array}{c}\text { Consumer } \\
\text { bus }\end{array}$ & 28509 & 28524 & 28537 & 28538 & 28562 & 28694 & 28709 & 28719 & 28729 \\
\hline Pro-rata & 6069.52 & 8080 & 3557.2 & 3472 & 0 & 2806.32 & 386 & 2050 & 3853.52 \\
\hline Bialek & 10160 & 3215.04 & 3265.52 & 3188.48 & 0 & 3166.56 & 63.36 & 0 & 3281.92 \\
\hline $\begin{array}{l}\text { Consumer } \\
\text { bus }\end{array}$ & 28730 & 28736 & 28737 & 28746 & 28747 & 28756 & 28774 & 28775 & 28787 \\
\hline Pro-rata & 1480.56 & 1757.76 & 4299.76 & 5354.4 & 2961.12 & 3772.4 & 4002.24 & 1805.04 & 3204.48 \\
\hline Bialek & 894.56 & 2264.88 & 606.56 & 7225.84 & 3921.92 & 5432.96 & 6853.76 & 1800.4 & 5569.52 \\
\hline $\begin{array}{c}\text { Consumer } \\
\text { bus }\end{array}$ & 28792 & 28795 & 28800 & 28808 & 28839 & 29102 & & & \\
\hline Pro-rata & 3495.2 & 2690.72 & 1737.44 & 5732.96 & 5627.36 & 975.44 & & & \\
\hline Bialek & 5694.16 & 0 & 990.56 & 1736.8 & 5047.52 & 0 & & & \\
\hline Total $[\$ / \mathrm{h}]$ & Pro rata & & 193231.9 & & Bialek & & 188 & 05.7 & \\
\hline
\end{tabular}

\section{Conclusions}

We suggest a simultaneous $N-1$ contingencies congestion management approach and transmission cost allocation among market participants. Two congestion solving corrective methods have been used in this case study: generated power re-dispatching and consumed power mitigation. It finds that the power generation reserves' availability and power system structure play a positive role in solving congestion. 
Transmission costs allocated to generators and consumers are computed using a developed software tool based on the Bialek and pro-rata methods. Power losses have been considered within this approach. Both methods are highly dependent on total system bus power injection. The values corresponding to the analyzed methods are different, due to different premises. Using the pro-rata method, transmission usage is distributed across all generating groups and PQ buses. With regard to the Bialek method, transmission usage is distributed to each generator and each consumer, through the power flow tracing mechanism.

The main contributions of this paper are as follows: base operating conditions computed by the authors, correspond with the ones managed by the Romanian Power Dispatcher; transmission tariff values are the ones used by the Romanian TSO, who is the main beneficiary of this study; methods have been implemented within a software tool developed in Mathematica environment; relations used for the pro-rata method have been adapted for the needs of Transelectrica (taking into consideration the ratio between the generating units / consumers contribution).

\section{Acknowledgements}

This work was partly supported by the strategic grant POSDRU/89/1.5/S/57649, Project ID 57649 (PERFORM-ERA), co-financed by the European Social Fund Investing in People, within the Sectoral Operational Programme Human Resources Development 2007-2013.

Also, this research was partly supported by the Romanian Power Grid Company "Transelectrica", in the framework of the research grant UPT No. 49 / 2011.

\section{References}

[1] Azadeh A., Saberi M., Nadimi V., Iman M., Behrooznia A.: An Integrated Intelligent Neuro-Fuzzy Algorithm for Long-Term Electricity Consumption: Cases of Selected EU Countries, Acta Polytechnica Hungarica, Vol. 7, No. 4, 2010, pp. 71-90

[2] Tao S., Gross G.: A Congestion-Management Allocation Mechanism for Multiple Transaction Networks, IEEE Transactions on Power Systems, Vol. 17, No. 3, August 2002, pp. 826-833

[3] Fu J., Lamont J. W.: A Combined Framework for Service Identification and Congestion Management, IEEE Transactions on Power Systems, Vol. 16, No. 1, February 2001, pp. 56-61

[4] Layden D., Jeyasurya B.: Integrating Security Constraints in Optimal Power Flow Studies, IEEE Transactions on Power Systems, Vol. 20, No. 2, May 2005, pp. 675-683

[5] Belmadani A., Benasla L., Rahli M.: The Dynamic Economic Dispatch including Wind Power Injection in the Western Algerian Electrical Power System, Acta Polytechnica Hungarica, Vol. 8, No. 5, 2011, pp. 191-204 
[6] Kumar A., Srivastava S. C., Singh S. N.: A Zonal Congestion Management Approach Using Real and Reactive Power Rescheduling, IEEE Transactions on Power Systems, Vol. 19, No. 1, February 2004, pp. $554-562$

[7] Fang R., David A.: Transmission Congestion Management, IEEE Transactions on Power System, Vol. 14, No. 3, August 1999, pp. 877-833

[8] Abhyankar A. R., Soman S. A., Khaparde S. A.: Optimization Approach to Real Power Tracing: An Application to Transmission Fixed Cost Allocation, IEEE Transactions on Power System, Vol. 21, No. 3, August 2006, pp. $1350-1361$

[9] Pan J., Teklu Y., Rahman S., Jun K.: Review of Usage-based Transmission Cost Allocation Methods under Open Access, IEEE Transactions on Power System, Vol. 15, No. 4, November 2000, pp. 1218-1224

[10] Ilic M. D., Yoon Y. T., Zobian A., Paravalos M. E.: Toward Regional Transmission Provision and its Pricing in New England, Utility Policy, Vol. 6, No. 3, 1997, pp. 245-256

[11] Shirmohammadi D., Gribik P. R., Law E. T. K., Malinowski J. H., O'Donnel R.: Evaluation of Transmission Network Capacity Use for Wheeling Transactions, IEEE Transactions on Power Systems, Vol. 4, No. 4, October 1989, pp. 1405-1413

[12] Shirmohammadi D., Rajogopalan C., Alward E. L., Thomas C. L.: Cost of Transmission Transactions: An Introduction, IEEE Transactions on Power Systems, Vol. 6, No. 4, November 1991, pp. 1546-1560

[13] Conejo A. J., Arroyo J. M., Alguacil N., Guijarro A. L.: Transmission Loss Allocation: A Comparison of Different Practical Algorithms, IEEE Transactions on Power Systems, Vol. 17, No. 3, August 2002, pp. 571-576

[14] Bialek J.: Topological Generation and Load Distribution Factors for Supplement Charge Allocation in Transmission Open Access, IEEE Transactions on Power Systems, Vol. 12, No. 3, November 1997, pp. 11851193

[15] Bialek J.: Allocation of Transmission Supplementary Charge to Real and Reactive Loads, IEEE Transactions on Power Systems, Vol. 13, No. 3, August 1998, pp. 749-754

[16] Bialek J.: Tracing the Flow of Electricity, IEE Proceedings C, Generation, Transmission and Distribution, Vol. 143, No. 4, July 1996, pp. 313-320

[17] Bialek J., Kattuman P.A.: Proportional Sharing Assumption in Tracing Methodology, IEE Proceedings C, Generation, Transmission and Distribution, Vol. 151, No. 4, July 2004, pp. 526-532 
[18] Strbac G., Kirschen D., Ahmed S.: Allocating Transmission System Usage on the Basis of Traceable Contributions of Generators and Load Flows, IEEE Transactions on Power Systems, Vol. 13, No. 2, May 1998, pp. 527-534

[19] Kirschen D., Allan R., Strbac G.: Contributions of Individual Generators to Loads and Flow, IEEE Transactions on Power System, Vol. 12, No. 1, February 1997, pp. 52-66

[20] Ng W. Y.: Generalized Generation Distribution Factors for Power System Security Evaluations, IEEE Transactions on Power Apparatus and Systems, Vol. PAS-100, No. 3, March 1981, pp. 1001-1005

[21] Kilyeni S., Pop O., Slavici T., Craciun C., Andea P., Mnerie D.: Transmission Cost Allocation Using the Distribution Factors Method, Proceedings of the $15^{\text {th }}$ IEEE Mediterranian Electromechanical Conference MELECON, April 25-28, 2010, Valletta, Malta, pp. 1093-1098

[22] Galiana F. D., Conejo A. J., Gil H. A.: Transmission Network Cost Allocation Based on Equivalent Bilateral Exchanges, IEEE Transactions on Power Systems, Vol. 18, No. 4, November 2003, pp. 1425-1431

[23] Pop O., Barbulescu C., Andea P., Jigoria-Oprea D., Coroiu F., Tirian O.: Comparison of Power System Tracing Cost Allocation Methods, Proceedings of the IEEE International Conference EUROCON, April 27-29, 2011, Lisbon, Portugal, pp. 1-4

[24] Conejo A. G., Galiana F. D., Kockar I.: Z-bus Loss Allocation, IEEE Transactions on Power System, Vol. 16, No. 1, February 2001, pp. 105-110

[25] Conejo A. J., Contreras J., Lima D. A., Padilha-Feltrin A.: Z-bus Transmission Network Cost Allocation, IEEE Transactions on Power System, Vol. 22, No. 1, February 2007, pp. 342-349

[26] Kilyeni S., Pop O., Prostean G., Craciun C.: Transmission Cost Allocation Based on Power Flow Tracing Using Z Bus Matrix, Proceedings of the $14^{\text {th }}$ International Conference on Harmonics and Quality of Power ICHQP 2010, Bergamo, Italy, September 26-29, 2010, pp. 1-6

[27] http://www.transelectrica.ro/5Piete/administrare.php\#

[28] Barbulescu C., Congestion Management in Free Energy Market Conditions, PhD Thesis, Politehnica University Timisoara, 2009

[29] Pop O., Contributions on the Tariff Access Assessment to the Transport System, PhD Thesis, Politehnica University Timisoara, 2009 